\title{
Errors : Detection and minimization in histopathology laboratories
}

\author{
Karki $\mathrm{S}^{1}$
}

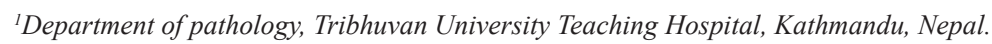

\author{
Keywords: \\ Audit; \\ Errors; \\ Quality control; \\ Surgical pathology.
}

\begin{abstract}
The histopathological diagnosis plays a major role in the treatment of diseases. Errors in these reports affect patient care. Hence, it is of utmost importance for all practitioners of this specialty to be aware of possible errors in histopathology laboratories and the means to minimize them. As with other disciplines of laboratory medicine, errors can occur in the pre-analytical, analytical and post analytical phase. The concept of quality and its control should be applied to all phases to curb errors. Audit can be used as a tool to generate information about the background level of errors in pathology which in turn can be used to reduce and avoid errors in histopathology laboratory. Furthermore, accreditation is a means to ensure patient safety and best quality assurance.
\end{abstract}

\section{INTRODUCTION}

Little specific attention was paid to errors in medicine before the 20th century. Poor results were attributed to fate, providence, bad luck or will of God. ${ }^{1}$ With the development of better normative standards and as techniques for better diagnosis and treatment improved throughout the $20^{\text {th }}$ century, expectations for better results also grew as did the recognition that medical errors were also a cause of some poor results. $^{2}$

During this period, concepts of legal liability improved and attitudes about medical liability and malpractice also developed. During the 1980s, few articles emerged on various aspects of the subject ${ }^{3}$ and particularly anesthesiology took steps to reduce errors in its own field ${ }^{4}$ In 1990s, medication errors were cited as a major cause of

\section{Correspondence:}

Dr. Shovana Karki, MBBS, MD

Lecturer, Departmnt of pathology

Tribhuvan University Teaching Hospital, Kathmandu, Nepal

Email:shovana_karki@hotmail.com morbidity and mortality ${ }^{5-8}$ and during the course several important publications concerning medical errors were published. ${ }^{9-12}$

The National Academics Institute of Medicine (IOM) in the USA estimates that approximately 44,000 to 98,000 deaths occur annually in that country alone due to medical errors. ${ }^{13}$ This has prompted joint commission on accreditation of health care organization to issue patient safety goals ${ }^{14}$ that include patient identification and effective communication among care givers in addition to many others. These goals apply to the field of histopathology as well. ${ }^{14}$

Because of its complex nature, anatomic pathology is prone to error at many steps throughout the testing process. Professional and technical human interactions are the usual source of quality control and error detection. ${ }^{15}$

The concept of quality control which is deeply rooted in most other disciplines of laboratory medicine is relatively young in histopathology department. Inherent qualities 
such as lack of objective numerical data, descriptive nature of reports, subjectivity, individual judgment and bias, non uniformity of reporting patterns etc make assessment and implementation of quality control more difficult in histopathology.

To document errors in histopathology laboratory, approach to error investigation and documentation using a validated tool has now been described. ${ }^{15}$ (table 1 )

\section{TYPES OF ERROR AND TEST CYCLE PHASE}

\section{Pre- analytical phase}

\section{Defective specimen includes:}

Lost specimen, inadequate volume, size, gross description, erroneous measurement or extraneous tissue.

Inadequate representativeness/sampling (tissue/blocks/ levels).

Patient ancillary diagnostic study not initially done.

\section{Defective identification includes:}

Patient

Tissue

Laterality (right vs left)

Anatomical location

Analytical phase

\section{Defective interpretation:}

False negative - undercall.

False positive - Overcall.

Misclassification - No altering primary or secondary diagnostic characteristics.

Primary meaning positive/negative or benign/malignant.

Secondary meaning grade, stage, margins etc.

Post analytical phase

Erroneous/missing non diagnostic information.

Dictation/typing error.

Report delivery.
Computer/format, transmission, upload error.

\section{CATEGORIES OF ERRORS}

Literature has described four general types of errors, with three subtypes in the category of defective interpretation. ${ }^{15}$

In the first major category of defective interpretation, the first subtype of error is false negative, second subtype false positive and third is misclassification e.g there is neither an undercall nor an overcall when a pathologist incorrectly labels an entity in the proper category of disease (e.g fibrosarcoma rather than malignant fibrous histiocytoma). The alternative designation alters neither the diagnostic primary classification (eg. malignancy) nor secondary diagnostic features (e.g high grade, negative margin) among the features mentioned in the report.

The second major category of error is constituted by defective identification of patient, tissue or laterality. These errors can take place at any step in the process of diagnosis. However, they are more common in the pre-analytical phase. This category encompasses misclassification of patients, origin of tissue, sample (e.g stomach vs colon), anatomic location (e.g ascending vs descending colon) or laterality of tissue (e.g right vs left breast).

The third category consists of specimen defects including lost specimens, inadequate volume and size occurring in the pre-analytical phase and inadequate gross description or measurement, extraneous tissue or inadequate sampling occurring in the pre- analytical phase. Pre-analytical phase specimen defects also includes specimens whose representativeness is inadequate or suboptimal at the tissue level, block or slide level because of an action or inaction taken or not taken in the surgical pathology laboratory. Failure to perform pertinent ancillary studies that would initially reveal a correct diagnosis is also a subtype of preanalytical specimen defect.

Fourth major category of error is defective reporting. This includes reports with erroneous or missing non diagnostic information (e.g clinician's name, date of procedure etc), dictation or typing error, report format or upload errors which can arise while using computers. Defective report error usually occurs in the post analytical phase, although missing or incorrect information may have been there in the pre-analytic phase without previously been addressed by anyone until the report's preparation and dispatch.

Documentation of the type of change made after an error was discovered should be made. Amendment options include changes in:

a) Primary diagnostic characters (e.g negative to positive, benign to malignant, inadequate to adequate). 
b) Secondary diagnostic characteristics.

c) Diagnostic reclassification.

d) Patient or specimen re-identification.

e) Report of additional specimen sampling that resulted in changed report.

f) Other edits that do not change primary or secondary diagnostic information, patient or specimen identification or involve specimen characteristics.

Timing of discovery is categorized into those errors detected before sign out and those after sign out. For those changes detected before sign out, mechanisms of discovery are:

a) Additional information or material.

b) Intradepartmental review sign-out or double read of the current case.

c) Preparation or presentation at a conference or at review with a clinician

d) External consultation.

For revision after sign out the mechanisms are:

a) The responsible pathologist's review of a recent case without additional information or material.

b) The responsible pathologist's review of a recent case with addition information or material but without clinician prompting.

c) At preparation or presentation at conference with clinicians (e.g tumor board).

d) Clinician initiated review or reconsideration of a case.

e) As a result of external consultation.

A part of error classification attempts to standardize assessment of outcomes related to anatomic pathology error. ${ }^{15}$ Taxonomy of outcome types divide consequence into :

a) No impact on care.

b) Impact on care with minimal harm.

c) Minor harm

d) Moderate harm and e) Major harm.

No impact indicates erroneous message not transmitted or message transmitted but ignored. Minimal harm means delay in diagnosis, unnecessary non invasive further diagnostic effort (e.g blood, radiograph, CT), delay in therapy and unnecessary therapy. Minor morbidity is defined as effects and events that can be demonstrated objectively (e.g fever, thrombocytopenia, swelling etc) but do not require hospitalization or surgical intervention. Moderate morbidity includes effects and events that require hospitalization or surgical intervention but not major morbidity defined as loss of organ or function of an organ system (e.g arm/limb, eye/sight, ear/hearing, speech or uterus of a woman of reproductive age). ${ }^{15}$

All process involved from the submission of specimen to preparation of slide is grouped under pre-analytical phase. Newer models for pre-analytical phase also include aspects like patient satisfaction, the collection process and professional staff satisfaction with arrangement made by the laboratory towards sample collection and transportation etc. $^{16}$

Studies have implied that most of the errors in the laboratory are related to pre-analytical phase. ${ }^{17}$ Same can be said of histopathology as well. ${ }^{18}$ Documented instructions containing relevant information should available at all points of specimen collection with the laboratory. Correct patients identification by a unique accession number traceable to the specimen and report all throughout the process is of chief importance. Error in this area is common but avoidable.

Similarly, wrong identification of anatomic location or laterality is an error that should be avoided. For this, it is worthwhile for the laboratory to design its own "referral form" for histopathology and immunohistochemistry if available and circulate it to areas of sample collection. ${ }^{19}$ This form should provide adequate space for relevant clinical data. When clinical data is not provided or not adequate, the laboratory should take imitative to obtain the pertinent data either from the treating physician or hospital files. Further to eliminate the errors in pre- analytical phase standard procedure for sample accession, identification, acceptance/ rejection, gross examination and all other following steps must be documented. The standard operating procedure should be maintained and be made available at workplace.

Planned changing of chemical used for processing should be based on tissues passed through. Once predetermined limit is reached, compulsory change should be done. This prevents under processing, unnecessary rework and loss of tissue. Same applies to deparaffinization, staining, dehydrating and cleaning steps of section preparation.

For hematoxylin and eosin, a tissue containing a mixture 
of hematoxyphilic and eosinophilic tissue (cervix, fibroadenoma ) is to be used as controls. Multiple sections may be cut and stored to be used as controls later. Using same controls avoids variation related to tissue type. Control slide staining should be done before the routine batch staining is done and the staining character should be compared with that of the previous day. A record of staining character should be maintained.

Microtome should be serviced regularly with periodic calibration of micrometer to maintain uniform section thickness. Use of disposable blades is recommended. Lastly, care should be taken not to introduce artifact during any phase of tissue processing and slide preparation.

In the post analytical aspect, report generation without transcription error, report transmission/dispatch to the correct person, storage of report material as well as reported data and safe disposal of specimen is looked into. Billing issues, patient safety issues, turnaround time (TAT) and general customer satisfaction (wait time) have been included in the post analytical phase. 16 It is of vital importance to monitor TAT and laboratories should try to achieve the goal of signing out the majority of the specimen within $48 \mathrm{hrs}$ of receipt of specimen. ${ }^{19}$

The diagnostic standard in histopathology laboratory can be maintained and improved by

- external quality assessment schemes (EQA).

- clinical audit

- laboratory accreditation

- continuting medical education (CME)

- clinicopathological case review meetings. ${ }^{20}$

These processes are related to each other, for example, feedback from EQA provides opportunity for continuous medical education and participation in EQA schemes enables compliance with accreditation standard. Diagnostic external quality assessment (EQA) schemes consist of circulating a "test" material to the participant. The "test" material is a histological section with relevant clinical information. Diagnosis and comments are returned to the organizer of the scheme and feedback of the performance is provided to the participant. EQA is an important educational means in histopathology. It has two components, one: viewing the material will be educational, two: quality assessment requires quantitative feedback to the participant which has educational value as it can provide unambiguous information on areas where continuous medical education (CME) is required and it can confirm the effectiveness of that education. ${ }^{20}$
The levels of error in diagnostic laboratory can be monitored by audit. Audit involves asking questions and collecting data about selected aspects of one's current practice. ${ }^{21}$ In other disciplines of pathology national and international standards have been developed against which performance of a laboratory can be measured.22-25 Precise technical standards for diagnostic pathology laboratory are harder to define, though some of the technical processes can be subjected to internal and /or external audit. Audit can assess laboratory speed, overall staining quality and work load for both the laboratory and individual pathologist. In 1991 the American Association of Directors of Anatomic and Surgical Pathology produced a list of recommended types of departmental audit (table 2). ${ }^{26}$

Studies have shown a lack of consensus amongst pathologist for a range of specimen type and have documented that a same pathologist can produce different reports when examining the same specimen on different occasion. ${ }^{27}$

A report on 2046 cases of colonic cancer examined by 22 histopathologist showed considerable observer variation in histological grading, Dukes' staging and the number of lymphnodes involved. ${ }^{28}$ Similar lack of consensus has been noted in the diagnosis of molar pregnancy ${ }^{29}$ and melanocytic lesion..$^{30}$ Many studies have shown a lack of consensus when applying scores or grades to pathological process. ${ }^{27,31-34}$

The baseline and background level of erroneous diagnosis have been examined in several audit studies. In one US study, where an extra pathologist, was specifically appointed to review all cases over a 1-year period, involving 5397 cases, 14 discrepancies $(0.26 \%)$ of potential clinical significance was detected. ${ }^{35}$

In a similar audit employing second pathologist, major errors was identified in $1.2 \%$ of 2694 cases. ${ }^{36}$ When a second checker pathologist was involved the discrepancies were divided into oversight errors where the pathologist had missed significant pathology and misinterpretation error where pathological changes had been incorrectly interpreted. $57 \%$ of the errors were oversight errors and $43 \%$ were misinterpretation errors in this study. ${ }^{35}$ Similarly in a 5 year audit at Southampton of 45 errors, $65 \%$ were due to misinterpretation, $31 \%$ due to pathological oversight and $4 \%$ due to failure to answer a specific clinical query. Almost all the errors in the reports were readily detected and corrected when it was brought to the notice of the reporting pathologist. Discussion with reporting pathologist suggested both oversight error and misinterpretation error occurred while reporting a large batch of surgical specimen. ${ }^{37}$ In other studies majority of pathologist indicated errors related to excessive workload. ${ }^{38}$

Peer review is one of the commonly used methods of audit. The use of an extra pathologist for dual reporting provides 


\begin{tabular}{l} 
Table 1: Approach to error investigation and documenta- \\
tion \\
\hline Type of error \\
Timing of discovery \\
\hline Discoverer \\
\hline Report revision \\
\hline Mechanism of discovery \\
\hline Outcome of error : initial Vs late
\end{tabular}

Table 2: Recommended forms of departmental audit

\begin{tabular}{|c|c|}
\hline Type of audit & Procedure \\
\hline $\begin{array}{l}\text { Intradepartmental consulta- } \\
\text { tion }\end{array}$ & $\begin{array}{l}\text { Review of selected cases by col- } \\
\text { leagues }\end{array}$ \\
\hline $\begin{array}{l}\text { Intra-operative } \\
\text { consultation(frozen section) }\end{array}$ & $\begin{array}{l}\text { Review of frozen sectio diagnoses in } \\
\text { the light of final paraffin section diag- } \\
\text { nosis }\end{array}$ \\
\hline Random case review & $\begin{array}{l}\text { Re-reporting of random sample from } \\
\text { all cases submitted. }\end{array}$ \\
\hline Clinical indicator audit & $\begin{array}{l}\text { Cases selected on a clinical basis are } \\
\text { all checked over a given period to } \\
\text { ensure consistency in diagnosis and } \\
\text { reporting }\end{array}$ \\
\hline $\begin{array}{l}\text { Intra and inter-departmental } \\
\text { conferences (Clinicopatho- } \\
\text { logical meetings) }\end{array}$ & $\begin{array}{l}\text { Review of cases presented to all con- } \\
\text { ferences; comparision of presented } \\
\text { diagnosis against reported diagnosis }\end{array}$ \\
\hline Inter-institutional review & $\begin{array}{l}\text { Comparision of local diagnoses with } \\
\text { outside review diagnoses }\end{array}$ \\
\hline $\begin{array}{l}\text { Surgical pathology turn- } \\
\text { around times }\end{array}$ & Audit of time taken to produce reports \\
\hline Specimen adequacy & $\begin{array}{l}\text { Monitor identification and processing } \\
\text { of specimens }\end{array}$ \\
\hline Lost specimens & $\begin{array}{l}\text { Monitor numbers of lost tissue speci- } \\
\text { men }\end{array}$ \\
\hline Histology quality control & $\begin{array}{l}\text { Assess times of delivery of slides and } \\
\text { adequacy of staining }\end{array}$ \\
\hline
\end{tabular}

continuous peer review but requires significant resources. Hence, random case audits are used to monitor errors. Random case audits a sample size of $2 \%$ to $4 \% .^{37,39}$

The other method of detecting error in pathology that is carried out in almost all pathology departments is the clinicopathological meeting. An audit of cases at clinicopathological meeting is relatively easy to establish and has a low resource requirement. ${ }^{40}$

Accreditation is an enabler of quality; it is patient focused, impartial and objective, and ensures an upto date technologies and it procedures that reflect current best practice. Hence, accreditation should also be implemented in histopathology laboratory to improve quality of service and to provide patient satisfaction.

\section{CONCLUSION}

Medicine is currently being challenged by society to improve patient safety and to significantly minimize medical errors. As surgical pathology plays an integral part in patient care it is essential for all practitioners of this specialty to detect and modify processes where possible to meet this growing need.

\section{REFERENCES}

1. Sharpe VA, Faden AI. Medical harm: Historical, conceptual and ethical dimensions of iatrogenic illness. New York, NY: Cambridge University Press; 1998. pp. 123-134. Crossref

2. Sirota RL. Error and error reduction in Pathology. Arch Pathol Lab Med 2005;129:1228-33. Crossref

3. Hilfiker D. Facing our mistakes.N Engl J Med 1984;310:118-122. Crossref

4. Gabba DM. Anaesthesiology as a model for patient safety in health care. BMJ 2000;320:785-8. Crossref

5. Leape LL, Brennan TA, Laird $\mathrm{N}$ et al. The nature of adverse events in hospitalized patients: results of Harvard Medical Practice Study II. N Engl J Med 1991;324:377-84. Crossref

6. Leape LL, Bates DW, Cullen DJ et al. System analysis of adverse drug events. JAMA 1995;274:35-43. Crossref

7. Bates DW, Spell N, Cullen DJ et al. The cost of adverse drug eventsin hospitalized patients. JAMA 1997;277:307-11. Crossref

8. Avorn J. Putting adverse drug events into perspective. JAMA 1997;277:341-2. Crossref

9. Leape LL. Error in medicine. JAMA 1994;272:1851-7. Crossref

10. Gaba D M. Human error in dynamic medical domains. In: Bogner MS, ed. Human Error in Medicine. Hillsdale, NJ: L, Eribsum Associates: 1994.pp197-224

11. De Leval M. Human factors and surgical outcomes: A Cartesian dream. Lancet 1997;349:723-5. Crossref

12. Derman H. Quality and liability issues with the Papanicolaou smear: lesson from the science of error prevention. Arch Pathol Lab Med 1997;121:287-91. Crossref

13. Kohn L, Corrigan J, Donaldson M eds. To err is human: Building a safer health system. Washington DC: National academics press; 2000. [Internet] Available from: Crossref

14. National patient safety goals. Joint commission on accreditation of health care organization. Available from : Crossref.

15. Zarbo RJ, Meier FA, Raab SS. Error detection in anatomic pathology. Arch Pathol Lab Med 2005;129:1237-45. Crossref

16. Hollensead SC, Lockwood WB, Elin RJ. Errors in pathology and laboratory medicine. Consequence and prevention. J Surg Oncol 2004;88:161-81. Crossref

17. Wiwanitkit V. Types and frequency of pre- analytical mistakes in the first Thai ISO 9002:1994 certified clinical laboratory. A six month monitering. BMJ Clin Pathol 2001;1:1-5. Crossref

18. Sharif MQ, Mushtaq S, Mamoon N, Jamal S, Luqman M. Clinician's responsibility in pre-analytic quality assurance of histopathology. Pak J Med Sci 2007;23:720-3.

19. Lyengar JN. Quality control in histopathology laboratory. An overview with stress on the need for a structured national external quality assessment scheme. Indian J Pathol Microbiol 2009;52:1-5. Crossref

20. The royal college of pathologist. recommendations for the development of histopathology /cytopathology external quality 
assessment schemes. April 1998.

21. Ramsay AD. Errors in histopathology reporting: detection and avoidance. Histopathology 1999;34:481-90. Crossref

22. Legg EF, Hursell AE.External quality assessment of quantitative urinary analysis. Ann. Clin. Biochem. 1984; 21: 491-3. Crossref

23. Chambers RE, Wicher JT, Bullock DG. External quality assessment of immunoassay for specific proteins in serum : 18 months experience in the United Kingdom. Ann Clin Biochem 1984;21:246-53. Crossref

24. Reed SE, Gardner PS, Snell JJS, Cha O. United Kingdom scheme for external quality assessment in virology. Part I. General method of operation. J Clin Pathol 1985;38:534-41. Crossref

25. Snell JJS, Brown DFJ, Phua TJ. Antimicrobial susceptibility testing of Haemophilus influenzae; a trail oragnized as part of the United Kingdom national external quality assurance scheme for microbiology. J Clin Pathol 1986;39:1006-12. Crossref

26. Association of Directors of Anatomic, Surgical Pathology Recommendations on quality control and quality assurance in anatomic pathology. Am J Surg Pathol 1991;15:1007-9. Crossref

27. Cocker J, Fox H, Langley FA. Consistency in histological diagnosis of epithelial abnormalities of the cervix uteri. J Clin Pathol 1968;21:67-70. Crossref

28. Morson BC. Histopathology reporting in large bowel cancer. Br. Med. J. 1981; 283 :1493. Crossref

29. Howart AJ, Beck S, Fox H et at. Can histopathologist reliably diagnose molar pregnancy? J. Clin. Pathol 1993;46:599-602. Crossref

30. Farmer ER, Gonin R, Hanna MP. Discordance in the histopathologic diagnosis of melanoma and melanocytic nevi between expert pathologists. Human Pathol 1998;29:100-2.
31. Buckely CH, Butler GB. Fox H. Cervical intraepithelial neoplasia. J Clin Pathol 1982;35:1-13. Crossref

32. Ismail SM, Colclough AB, Dinnen JS. Observer variation in histopathological diagnosis and grading of cervical intraepithelial neoplasia. Br Med J 1989;298:707-10. Crossref

33. Beck JS and members of MRC breast tumor pathology panel. Observer variation in reporting breast lesions. J Clin Pathol 1985;38:1358-65. Crossref

34. Foucar E. Do pathologists play dice? Uncertainty and early histopathological diagnosis of common malignancies. Histopathology 1997;31:495-502. Crossref

35. Safrin RE, Bark CJ. Surgical pathology signout: routine review of every case by a second pathologist. Am J Surg Pathol 1993;17:11902. Crossref

36. Lind AC, Bewtra C, Healy JC, Sirus KL. Prospective peer review in surgical pathology. Am J Clin Pathol 1995;104:560-6. Crossref

37. Ramsay AD, Gallaghen PJ. Local audit of surgical pathology: 18 months experience of peer review based quality assessment in an English teaching hospital. Am J Surg Pathol 1992;44:10-5. Crossref

38. Furness PN, Couder I. A questionnaire based survey of errors in diagnostic histopathology throughout the united kingdom. J Clin Pathol 1997;50:457-60. Crossref

39. Zuk JA, Kenyon WE, Myskow MW. Audit in histopathology; description of an internal quality assessment scheme with analysis of preliminary results. J Clin Pathol 1991;44:10-5. Crossref

40. McBroom HM, Ramsay AD. The clinicopathological meeting. A means of auditing diagnostic performance. Am J Surg Pathol 1993;17:75-80. Crossref 